\title{
Assessing the RELAP5-3D Heat Conduction Enclosure Model
}

\author{
Larry D. McCann
}

\section{NOTICE}

This report was prepared as an account of work sponsored by an agency of the United States Government. Neither the United States Government nor any agency thereof, nor any of their employees, nor any of their contractors, subcontractors or their employees, makes any warranty, express or implied, or assumes any legal liability or responsibility for the accuracy, completeness, or any third party's use or the results of such use of any information, apparatus, product, or process disclosed, or represents that its use would not infringe privately owned rights. Reference herein to any specific commercial product, process, or service by trade name, trademark, manufacturer, or otherwise, does not necessarily constitute or imply its endorsement, recommendation, or favoring by the United States Government or any agency thereof or its contractors or subcontractors. The views and opinions of authors expressed herein do not necessarily state or reflect those of the United States Government or any agency thereof. 


\title{
Assessing the RELAP5-3D Heat Conduction Enclosure Model
}

\author{
Larry D. McCann
}

\begin{abstract}
Three heat conduction problems that have exact solutions are modeled with RELAP5-3D using the conduction enclosure model. These comparisons are designed to be used in the RELAP5-3D development assessment scheduled to be completed in 2009. It is shown that with proper input choices and adequate model detail the exact solutions can be matched. In addition, this analysis identified an error and the required correction in the cylindrical and spherical heat conductor models in RELAP5-3D which will be corrected in a future version of RELAP5-3D.
\end{abstract}

\section{INTRODUCTION}

As discussed in last year's RELAP5 International User’s Seminar (Bayless, 2007), INL and ISL are currently jointly performing a development assessment of RELAP5-3D. One of the phenomenological problem categories included in the assessment is the conduction enclosure model.

The first application of the heat conduction enclosure model was the RBMK reactor (Paik, 1999). However, it was decided that, for the development assessment, it would be preferable to compare the RELAP5-3D conduction enclosure model calculations to exact solutions of the heat conduction equation.

Three cases were chosen for comparison to RELAP5-3D: (1) steady-state two-dimensional heat conduction in a rectangular solid; (2) transient one-dimensional conduction in a long, thin rod; and, (3) transient two-dimensional conduction in a rectangular solid. This paper first discusses considerations in using the heat conduction enclosure model, followed by discussion of the development of the models and comparisons between RELAP5-3D and the exact solutions to the transient heat conduction equation.

\section{HEAT CONDUCTION ENCLOSURE MODEL}

The RELAP5-3D heat structures represent only radial temperature variation, so they are one-dimensional heat conductors. The heat conduction enclosure model option in RELAP5-3D allows two or more heat structures in the input model to be connected directly at either of the radial surfaces. The user must provide a thermal conductance and view factor for each connection. The conductance should represent the actual equivalent heat transfer coefficient. The view factor should be the ratio of actual heat transfer area to the surface area for each conductor.

There are three significant limitations to the heat conduction enclosure model, as compared to a true multidimensional heat conduction model.

(1) For axial conduction, the connection can only be at one of the radial faces, not at each radial mesh point as it should be. Therefore, use of the heat conduction enclosure model for axial conduction may only be accurate enough to demonstrate whether axial conduction is important in a particular application. 
Idaho Falls, ID

November 18-20, 2008

(2) The heat conduction enclosure model heat flux is advanced in time explicitly. For radial conduction enclosure connections, calculational stability can be affected by the choice of conductance. If there is real thermal resistance modeled, such as a gap, then that should be used and should result in stable calculations. However, problems can arise if the two conductors are in physical contact and a very large conductance is appropriate.

(3) The conductance is time-invariant. Therefore any thermal conductivity used in calculating the conductance should represent an average value over the transient.

Although the axial limitation and the time-invariant conductance are unavoidable, there is a rule of thumb that can be applied to help choose a conductance value for conductors in contact that gives stable calculations. That rule of thumb is Equation (1).

$$
\text { Conductance }<\left(0.5(\Delta \mathrm{x})^{2} /(\alpha \Delta \mathrm{t})-1\right)(\mathrm{k} / \Delta \mathrm{x})
$$

Equation (1) was derived from guidance on computational stability in explicit numerical integration of the heat conduction equation (Incropera, 1985).

\section{RELAP5-3D COMPARED TO CONDUCTION MODEL SOLUTIONS}

In the following sections three conduction problems which are exact solutions to the heat conduction equation will be discussed. Each problem will be described, the equation for its exact solution presented, the RELAP5-3D model will be summarized and the calculational results compared in the following sections. The stability check for each problem will also be discussed.

In order to derive exact solutions to the heat conduction equation, simplifying assumptions are usually required. Some of those assumptions tend to be consistent with the limitations in the RELAP5-3D heat conduction enclosure model. For example, in the three exact solutions analyzed in this paper, all assume time invariant conductance. In addition, the long thin rod assumes constant temperature over the cross section, which is consistent with the limitation in the heat conduction enclosure model that connections can only be made at the radial faces. Thus, real problems may not be predicted as accurately as those analyzed in this paper.

\section{Problem 1: Steady-State Temperature in a Rectangle}

The steady-state temperature distribution in a rectangle (no temperature dependence on the $3^{\text {rd }}$ dimension) using Cartesian coordinates with three sides held at temperature $T_{\infty}$ and the fourth side at $T_{0}$ is described by Equation (2) (Carslaw, 1959).

$T(x, y)-T_{\infty}=\frac{4\left(T_{0}-T_{\infty}\right)}{\pi} \sum_{n=0}^{\infty} \frac{1}{(2 n+1)} \sin \frac{(2 n+1) \pi x}{a} \sinh \frac{(b-y)(2 n+1) \pi}{a} \operatorname{csch} \frac{(2 n+1) \pi b}{a}$

The rectangle goes from 0 to $\mathrm{a}$ in the $\mathrm{x}$ dimension and 0 to $\mathrm{b}$ in the $\mathrm{y}$ dimension. In this example, the value for $\mathrm{a}$ is 0.92 and the $\mathrm{b}$ value is 1.0 .

In the RELAP5-3D model, 25 heat structures were developed with 25 axial and 1 radial conductors in each. The heat conduction enclosure model was used to connect the heat structures to one another both radially and axially. The radial conductance used was chosen to be large to reflect excellent contact between the two conductor surfaces. The conductance value used was chosen to maintain temperatures in radial mesh points in contact within $1 \mathrm{~K}$ of each other. The conductance axially is the metal thermal conductivity divided by the distance between heat conductor centers.

A RELAP5-3D model without the axial heat conduction provided by the heat conduction enclosure model calculates linear temperature variation in the y-coordinate between the temperature at 0 and the temperature at 1.0 . The heat conduction enclosure model is needed to connect the axial conductors to the lower temperatures at the ends of the $\mathrm{x}$-coordinates of the rectangle. That heat transfer causes the non-linear temperature response. 
Idaho Falls, ID

November 18-20, 2008

The 5 figures below compare temperatures at 5 slices in the rectangle. The slices are at $\mathrm{x}$ values of $0.02,0.18$, 0.5 , and 0.82 , and 0.90 . Addition of the heat conduction enclosure model improves the RELAP5-3D temperature prediction considerably from a linear response. The agreement between RELAP5-3D and the exact solution is excellent. To obtain this level of agreement, it is necessary to provide 25 mesh points in the both the axial and radial directions. A case with 5 mesh points in each direction resulted in the RELAP5-3D results nearly double the exact solution near the center of the rectangle.

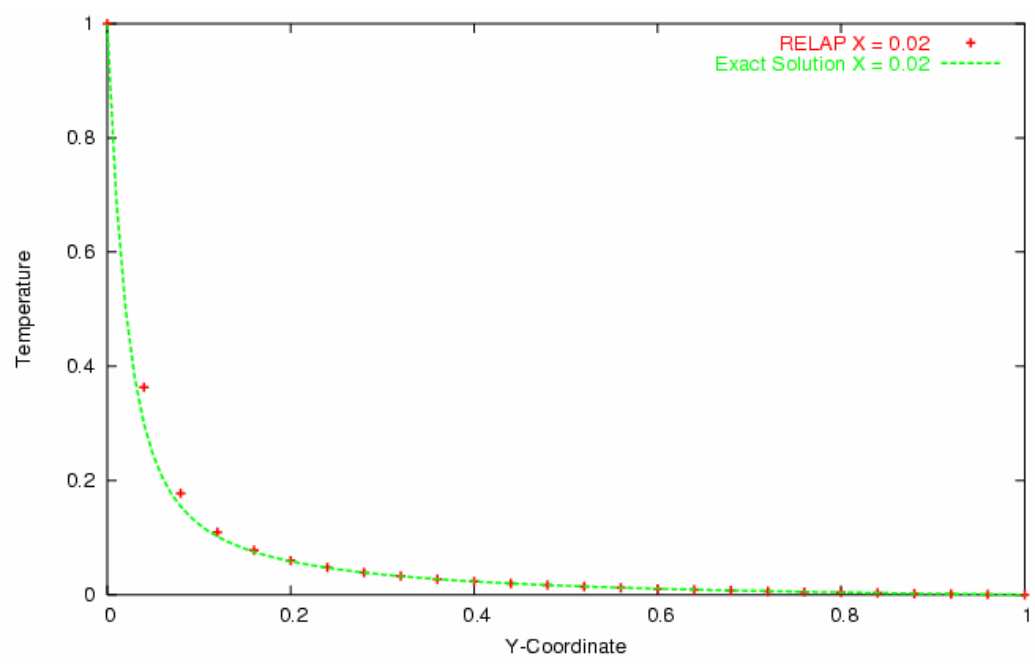

FIGURE 1. Comparison of RELAP5-3D to Exact Solution at $\mathrm{x}=0.02$.

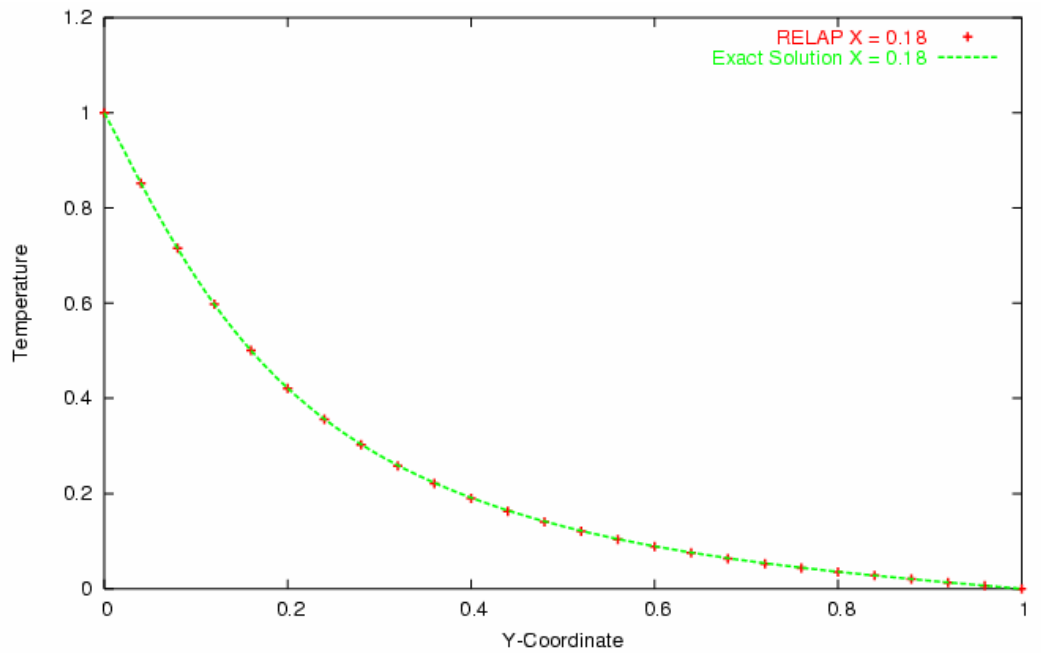

FIGURE 2. Comparison of RELAP5-3D to Exact Solution at $\mathrm{x}=0.18$. 
Idaho Falls, ID

November 18-20, 2008

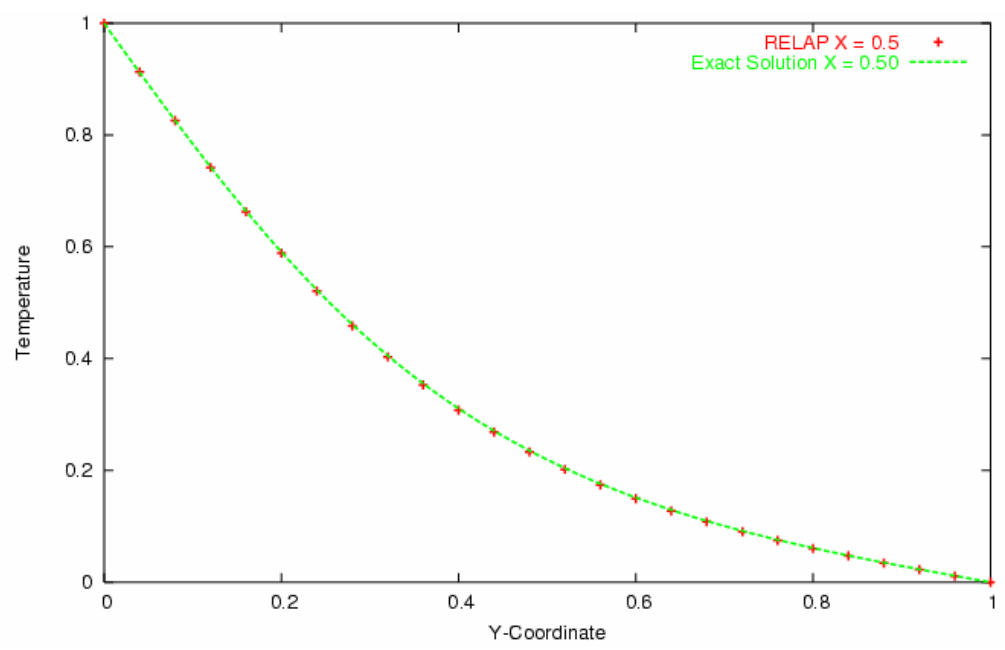

FIGURE 3. Comparison of RELAP5-3D to Exact Solution at $x=0.5$.

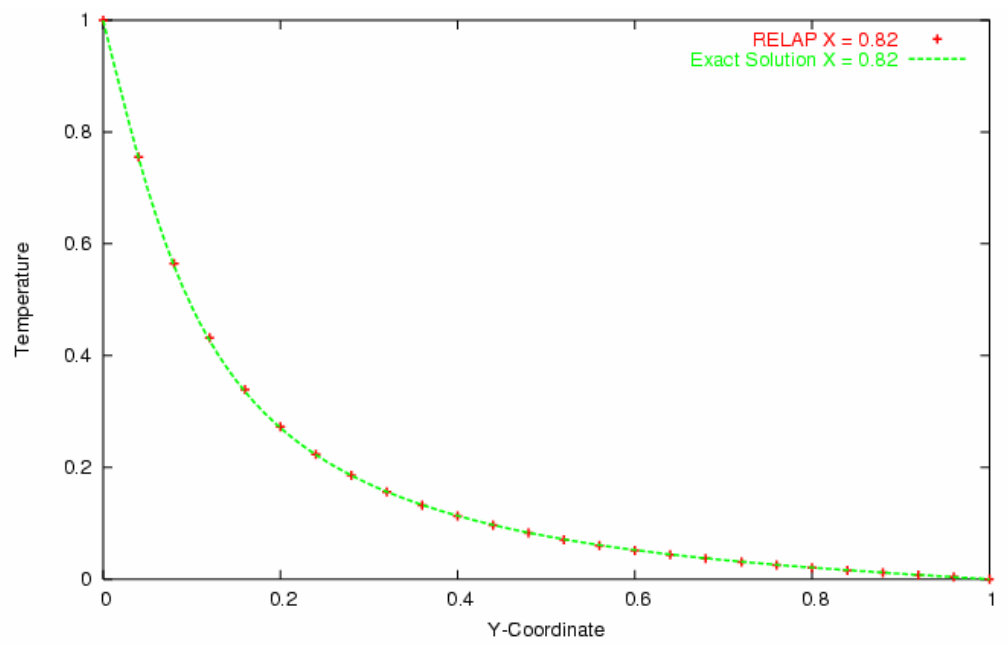

FIGURE 4. Comparison of RELAP5-3D to Exact Solution at $\mathrm{x}=0.82$.

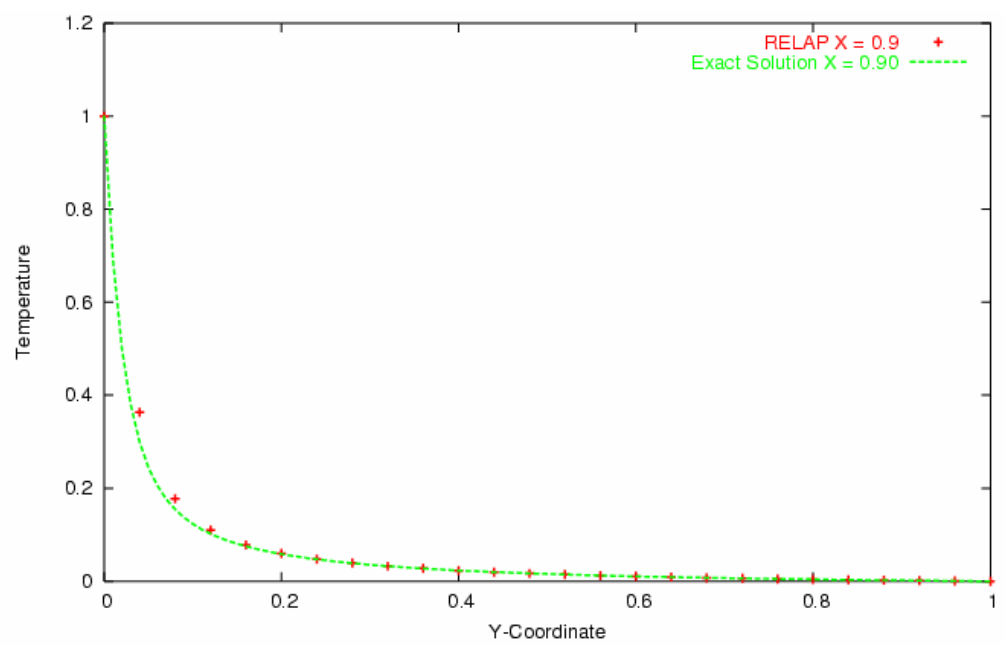

FIGURE 5. Comparison of RELAP5-3D to Exact Solution at $\mathrm{x}=0.90$. 
Idaho Falls, ID

November 18-20, 2008

The stability rule of thumb, Equation (1), applied to the RELAP5-3D model for Problem 1 indicates that the time step size should be less than 0.00015 second. The results in Figures 1 through 5 were determined using a time step size of 0.0001 second. When the time step size is increased to 0.0002 second, which violates Equation (1), a floating overflow occurs causing the problem to fail. When a time step size of 0.00005 second is used the results are identical to those in Figures 1 through 5.

\section{Problem 2: Transient One-Dimensional Conduction}

The exact solution to a transient temperature distribution in a thin rod (temperature dependence in only one dimension) using Cylindrical coordinates is compared to RELAP5-3D results using the heat conduction enclosure model. The $\mathrm{x}$-coordinate is in the axial direction in the rod and extends from $\boldsymbol{\ell}$ to $\boldsymbol{\ell}$. The rod has temperature $\mathrm{T}_{0}$ at both ends and convection from the sides of the rod to the surroundings which are at constant temperature $T_{\infty}$. The exact solution is described by Equation (3) (Carslaw, 1959).

$T(x, t)-T_{\infty}=\left(T_{0}-T_{\infty}\right) \frac{\cosh \left(x(v / \alpha)^{1 / 2}\right)}{\cosh \left(l(v / \alpha)^{1 / 2}\right)}-\frac{4\left(T_{0}-T_{\infty}\right)}{\pi} \sum_{n=0}^{\infty} \frac{(-1)^{n} e^{-v t-\left[\alpha(2 n+1)^{2} \pi^{2} t / 4 l^{2}\right]} \cos ((2 n+1) \pi x / 2 l)}{(2 n+1)\left[1+\left\{4 v l^{2} /\left((2 n+1)^{2} \pi^{2} \alpha\right)\right\}\right]}$

A RELAP5-3D model was developed to compare against the solution above. The rod represented has a 0.0254 meter diameter circular cross section and is 3 meters long $(\ell=1.5$ meter). The cylindrical conduction option is used in RELAP5-3D. Only two radial mesh points are used since the exact solution is based on the assumption of constant temperature at all points in a cross section. The rod is modeled with 60 equal axial sections. An additional 0.05 meter of length held at constant temperature is included attached to either end to represent the temperatures forced at the ends. Axial conduction is represented using the heat conduction enclosure model with the conductivity equal to the thermal conductivity divided by the axial height between the centers of adjacent sections in the heat conductor. The view factor used in the heat conduction enclosure model is the ratio of rod cross-sectional area to the surface area for an axial section in the heat conductor input. At the two ends, the axial height to the end is half the height of a conductor. This is accounted for by using the same conductivity with double the view factor at the two ends. In this case $T_{0}$ is set at $550 \mathrm{~K}$ and $T_{\infty}$ is $300 \mathrm{~K}$. The material properties used are for carbon steel at 478 K.

The temperatures are symmetric about the rod center, so only plots of temperatures between -1.5 meter and 0 are presented. Plots on the following pages compare RELAP5-3D heat structure volume averaged temperatures to exact solutions corresponding to the center of the heat structure and the two ends of the heat structure. In all cases the comparison with the axial conductor center temperatures is excellent.

In order to obtain this agreement a correction to RELAP5-3D was required. The transient response of the RELAP5-3D calculation without the correction was about twice as fast as it should be (time constant approximately half as large as it should be). The investigation into this problem revealed that the transient response with Cartesian coordinates matched the exact solution very closely. It was also found that the more radial mesh points in the model the closer the calculation matched the expected transient behavior. It was finally determined that the heat capacity was not correctly calculated at the outer mesh interval of a cylindrical heat structure. This same error was found in the spherical heat structure. After this was corrected, the results presented in Figures 6 through 11 were obtained. 
Idaho Falls, ID

November 18-20, 2008

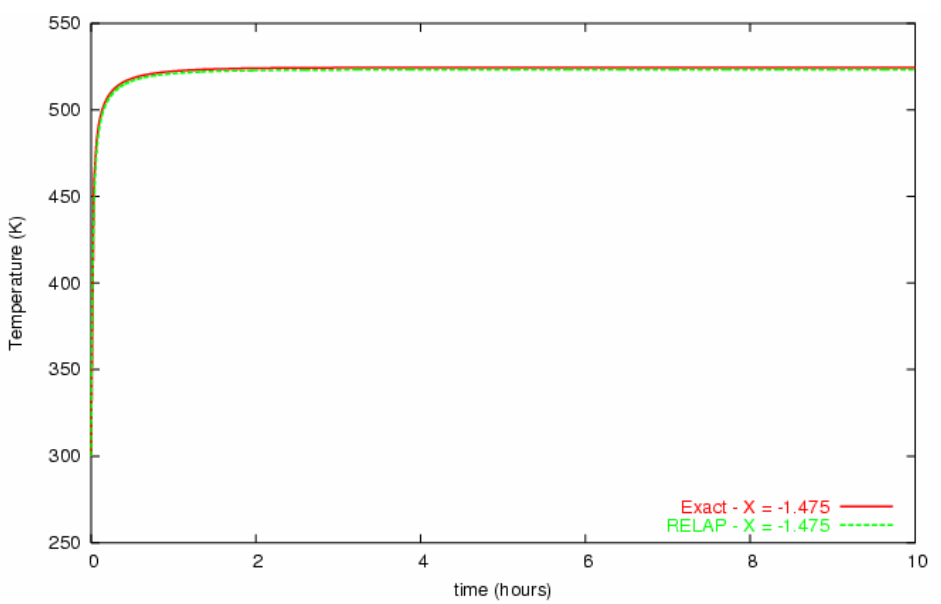

FIGURE 6. Comparison of RELAP5-3D to Exact Solution $2.5 \mathrm{~cm}$ from the Rod End.

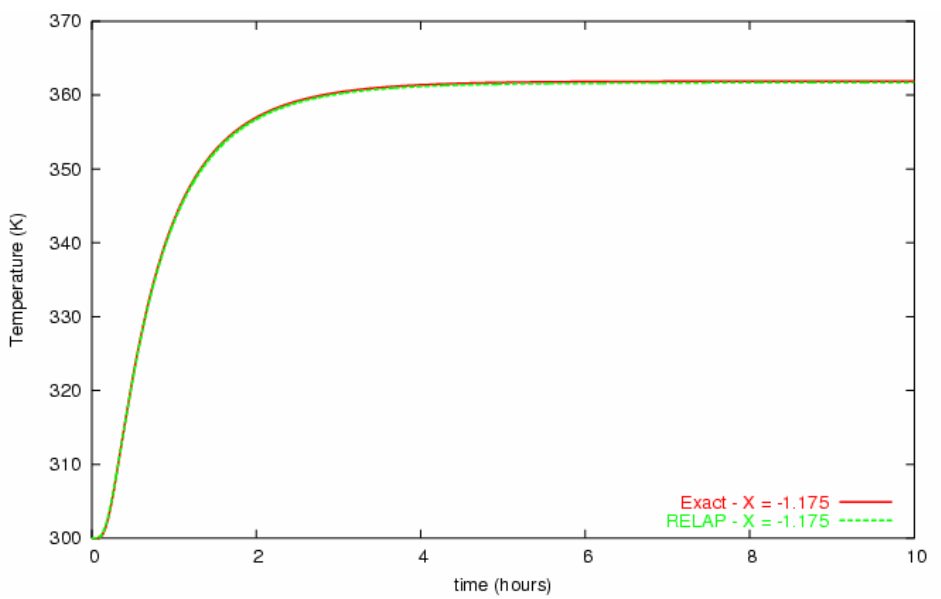

FIGURE 7. Comparison of RELAP5-3D to Exact Solution $32.5 \mathrm{~cm}$ from the Rod End.

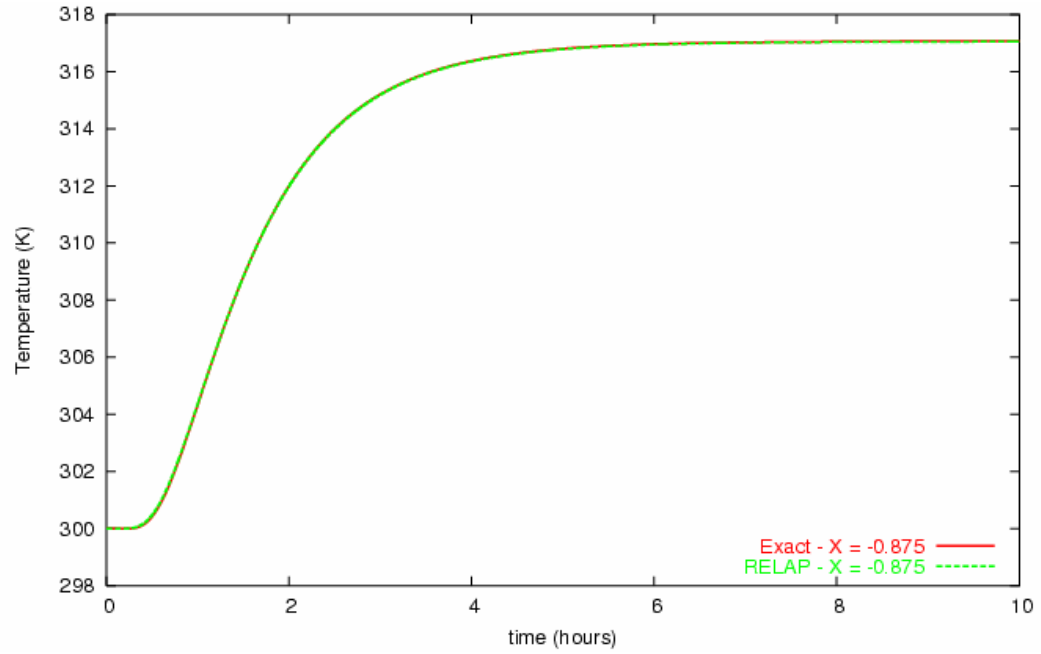

FIGURE 8. Comparison of RELAP5-3D to Exact Solution $62.5 \mathrm{~cm}$ from the Rod End. 


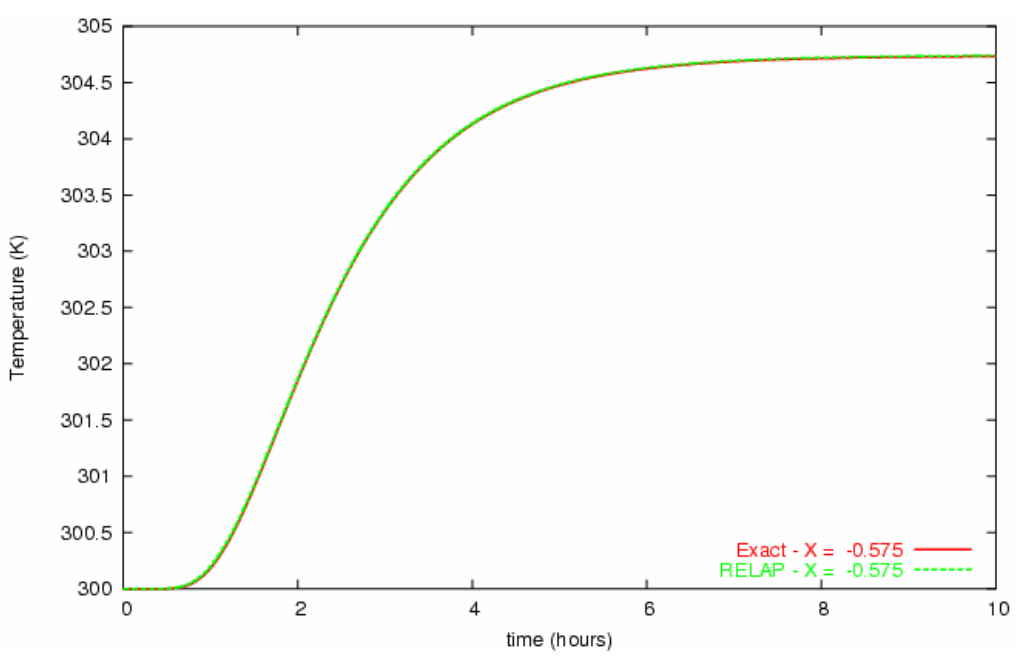

FIGURE 9. Comparison of RELAP5-3D to Exact Solution $92.5 \mathrm{~cm}$ from the Rod End.

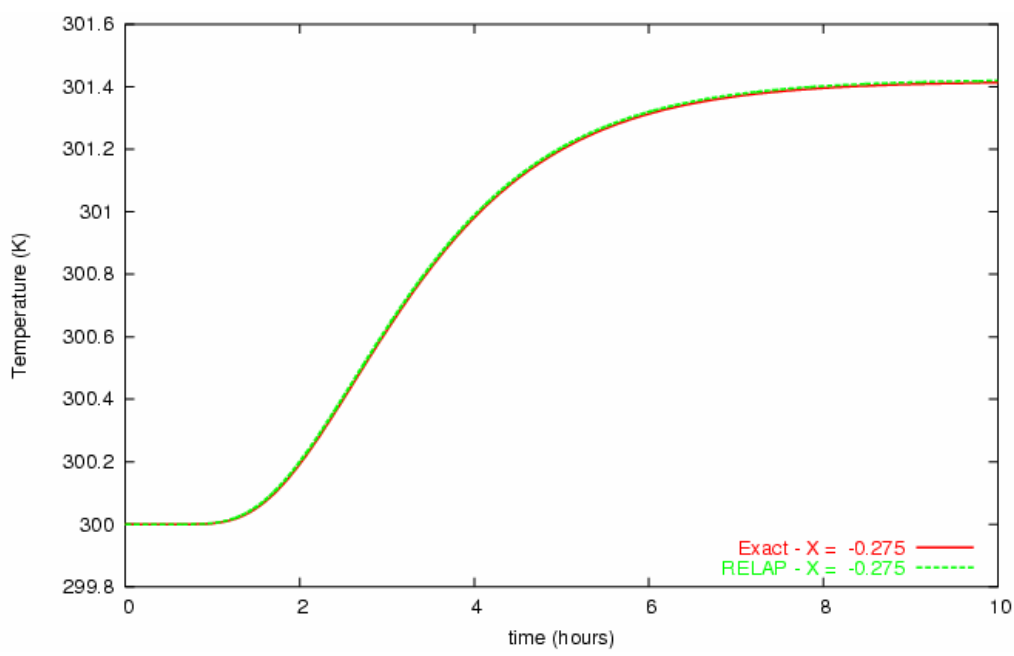

FIGURE 10. Comparison of RELAP5-3D to Exact Solution $122.5 \mathrm{~cm}$ from the Rod End.

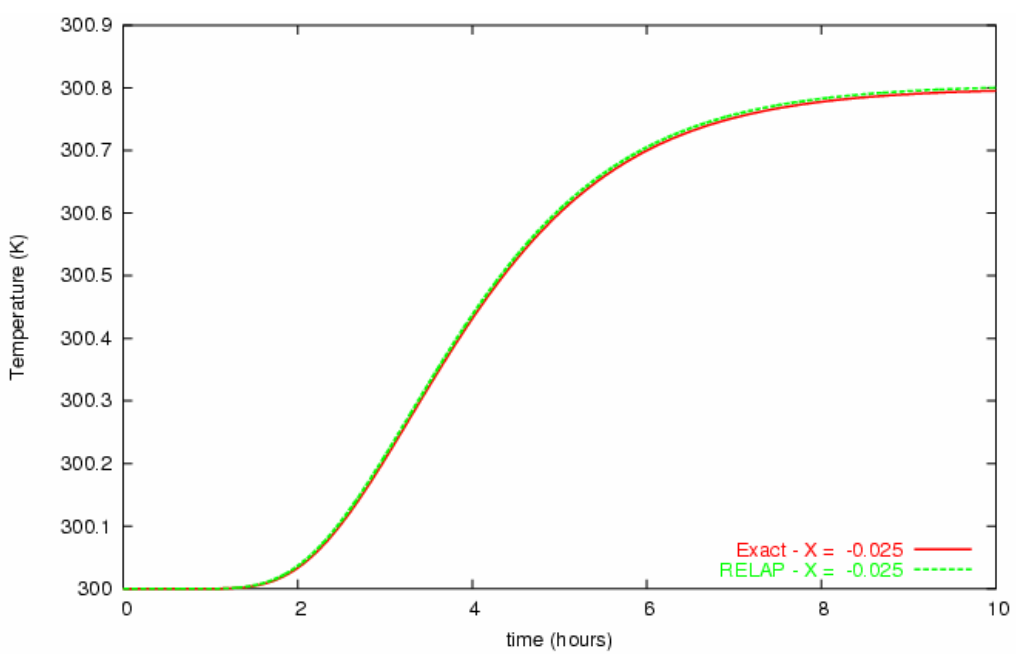

FIGURE 11. Comparison of RELAP5-3D to Exact Solution $147.5 \mathrm{~cm}$ from the Rod End. 
Idaho Falls, ID

November 18-20, 2008

For Problem 2, the stability rule of thumb, Equation (1), indicates that the time step size should be less than 95 seconds. The results in Figures 6 through 11 were determined using a time step size of 1 second. Results that look identical to those in Figures 6 through 11 when plotted on the same figures are obtained when using a 60 second time step size. When the time step size is increased to 120 seconds, which violates Equation (1), the temperatures oscillate between $\pm 10^{38} \mathrm{~K}$, starting at about 9 hours in the transient.

\section{Problem 3: Transient Two-Dimensional Conduction}

The exact solution to a transient temperature distribution in a rectangle (temperature dependence in two dimensions) using Cartesian coordinates is compared to RELAP5-3D results using the heat conduction enclosure model. The $x$-coordinate is in the axial direction in the rectangle and extends from $\ell$ to $\boldsymbol{l}$. The $y$-coordinate is in the radial direction and extends from $-b$ to $b$. The rectangle is initially uniformly at temperature $T_{0}$ with the temperature at all four sides forced to be constant temperature $T_{\infty}$. The exact solution is described by Equation (4) [Carslaw].

$$
\frac{\mathrm{T}(\mathrm{x}, \mathrm{t})-\mathrm{T}_{\infty}}{\left(\mathrm{T}_{0}-\mathrm{T}_{\infty}\right)}=\frac{16}{\pi^{2}}\left(\sum_{\mathrm{n}=0}^{\infty} \frac{(-1)^{\mathrm{n}} \mathrm{e}^{-\left[\alpha(2 \mathrm{n}+1)^{2} \pi^{2} \mathrm{t} / 41^{2}\right]} \cos ((2 \mathrm{n}+1) \pi \mathrm{x} / 2 \mathrm{l})}{(2 \mathrm{n}+1)}\right)\left(\sum_{\mathrm{n}=0}^{\infty} \frac{(-1)^{\mathrm{n}} \mathrm{e}^{-\left[\alpha(2 \mathrm{n}+1)^{2} \pi^{2} \mathrm{t} / 4 \mathrm{~b}^{2}\right]} \cos ((2 \mathrm{n}+1) \pi \mathrm{y} / 2 \mathrm{~b})}{(2 \mathrm{n}+1)}\right)
$$

A RELAP5-3D model was developed to compare against the solution above. The rectangle represented has the same dimensions of Problem 1 with a 0.46 meter $\boldsymbol{\ell}$ value and 0.5 meter b value. The axial and radial heat structures are identical to Problem 1. The initial temperature is $550 \mathrm{~K}$ in all structures. The temperatures of the end axial conductors are held at a constant temperature of $300 \mathrm{~K}$. The left and right boundaries are held at $300 \mathrm{~K}$ as well. Both axial and radial conduction are represented using the heat conduction enclosure model. Axially, the conductivity is equal to the thermal conductivity divided by the axial height between the centers of adjacent sections in the heat conductor. The conductivity needs to be much larger (offers negligible resistance) in the radial direction than the heat structure conductivity because the RELAP5-3D heat structure calculates the correct radial conductivity. The value chosen results in adjacent conductor surfaces remaining within about $0.01 \mathrm{~K}$ of each other, yet maintaining stable calculations with a 0.1 second time step size. At the two ends, the axial height to the end is half the height of a conductor. This is accounted for by using the same conductivity with double the view factor at the two ends. Like Problem 2, $\mathrm{T}_{0}$ is set at $550 \mathrm{~K}$ and $T_{\infty}$ is $300 \mathrm{~K}$. The material properties used are for carbon steel at $400 \mathrm{~F}(478 \mathrm{~K})$.

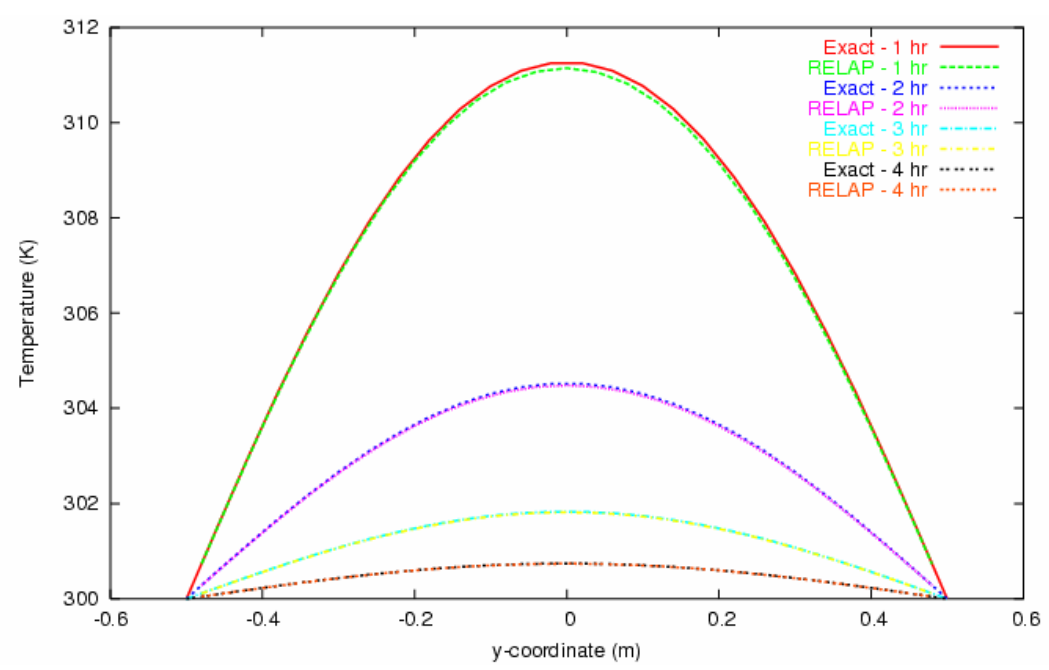

FIGURE 12. Comparison of RELAP5-3D to Exact Solution $2 \mathrm{~cm}$ from the Rod End. 


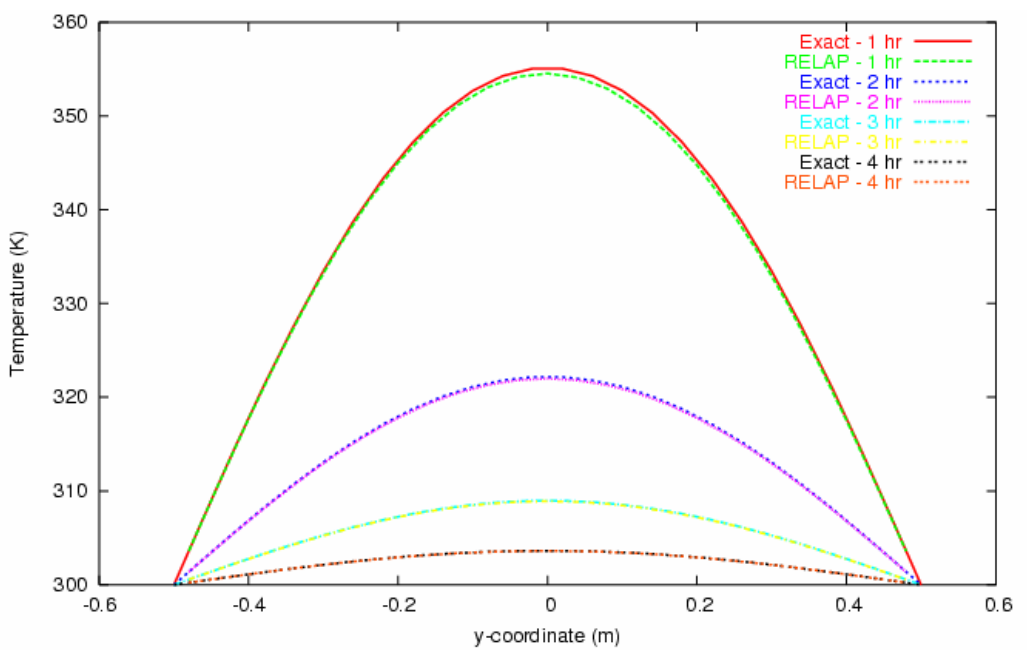

FIGURE 13. Comparison of RELAP5-3D to Exact Solution $10 \mathrm{~cm}$ from the Rod End.

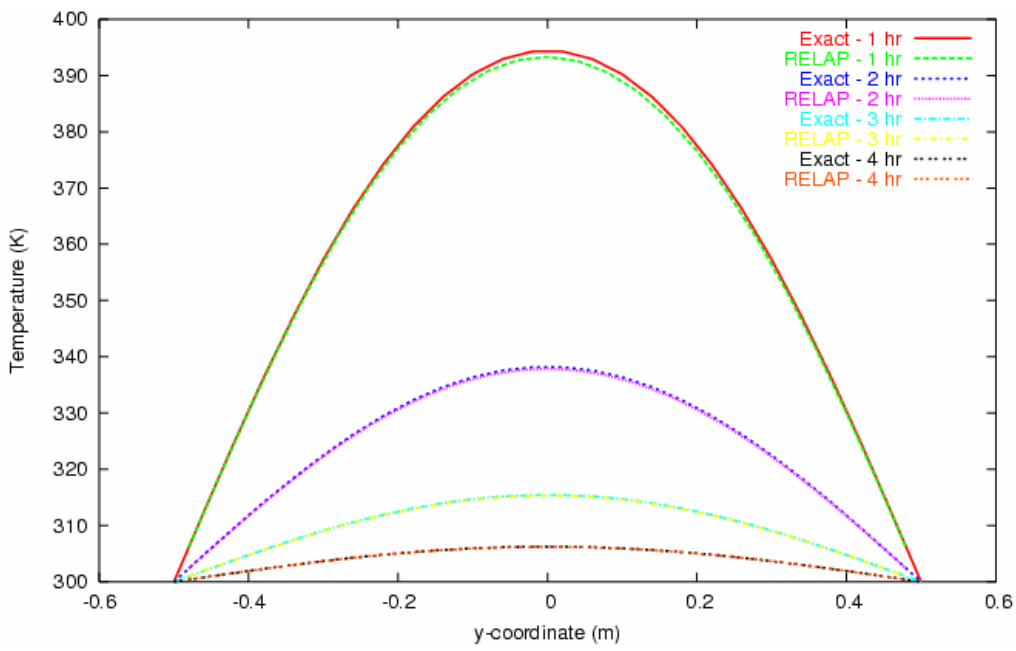

FIGURE 14. Comparison of RELAP5-3D to Exact Solution $18 \mathrm{~cm}$ from the Rod End.

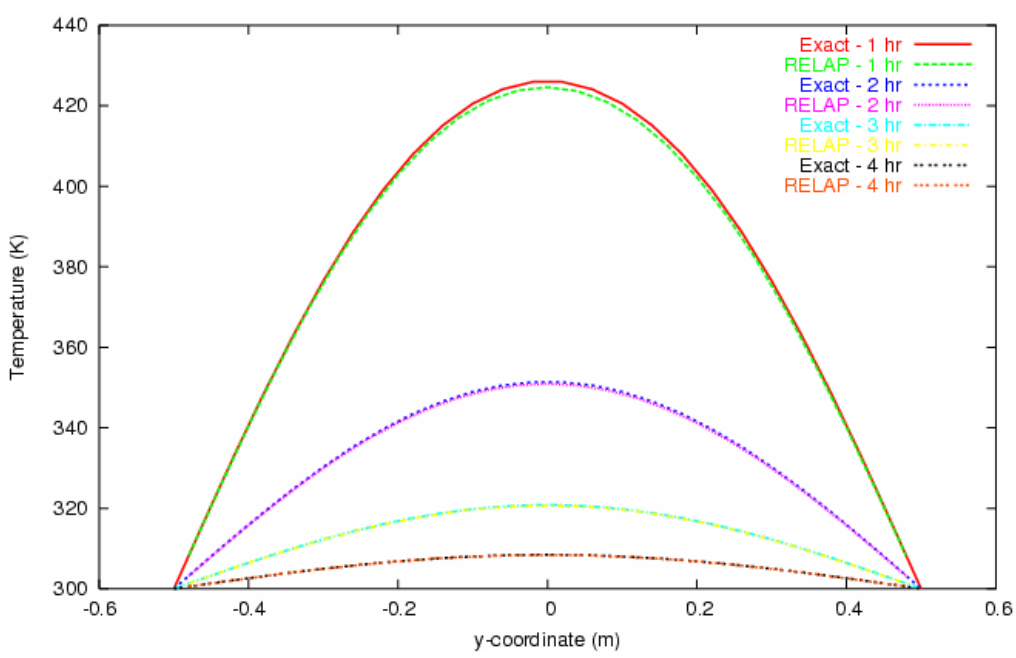

FIGURE 15. Comparison of RELAP5-3D to Exact Solution $26 \mathrm{~cm}$ from the Rod End. 


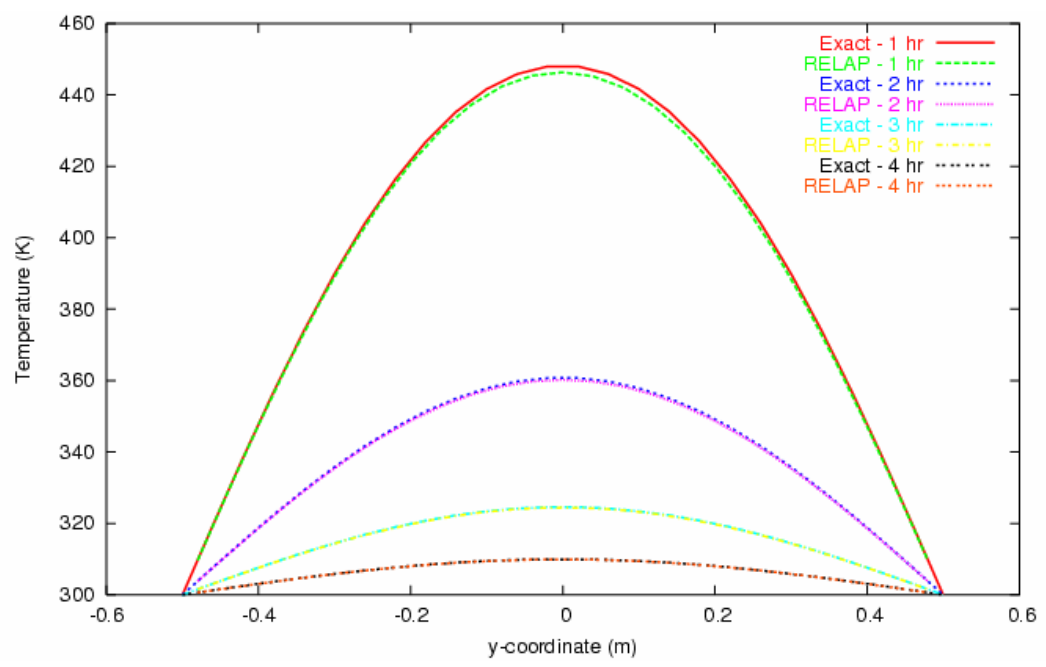

FIGURE 16. Comparison of RELAP5-3D to Exact Solution $34 \mathrm{~cm}$ from the Rod End.

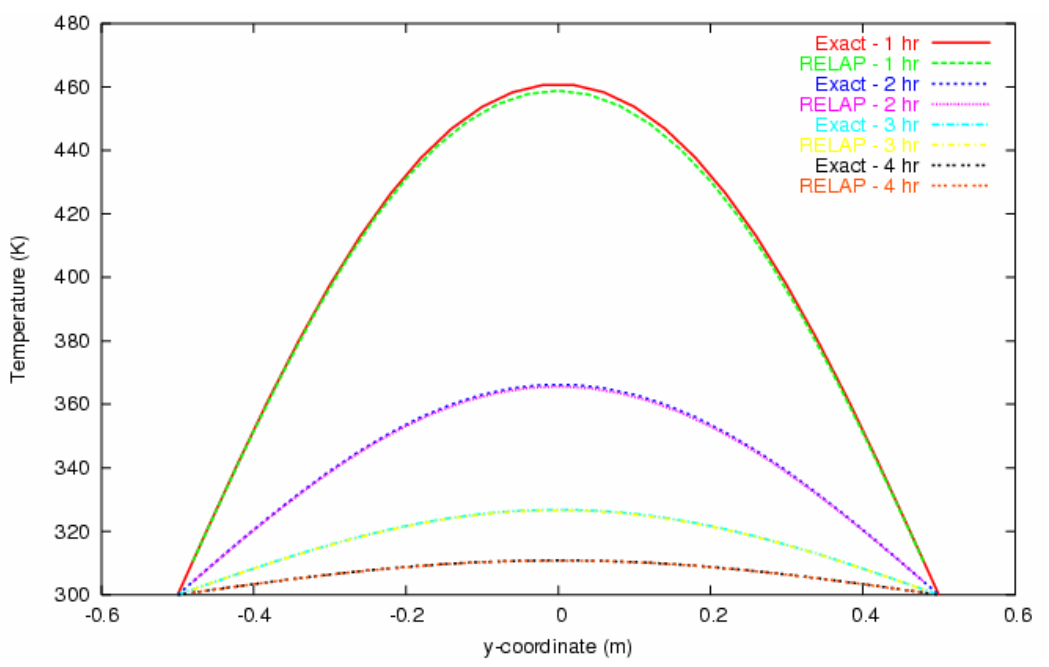

FIGURE 17. Comparison of RELAP5-3D to Exact Solution $46 \mathrm{~cm}$ from the Rod End.

Figures 12 through 17 compare RELAP5-3D radial (y-coordinate) temperature variation at several axial (xcoordinate) locations to exact solutions corresponding to the center of a RELAP5-3D heat structure. Each plot compares the temperature variation with axial position at four snapshots in time. In all cases the comparison with the axial conductor center temperatures is excellent.

For Problem 3 the Equation (1) rule indicates that the time step should be less than 0.166 second. Figures 12 through 17 are based on a model run a 0.1 second. To test time steps close to the rule from Equation (1), the RELAP5-3D model was run with a maximum time step of 0.16 seconds and with a maximum time step of 0.17 second. The results from the 0.16 second case are identical to the 0.1 second maximum time step case when plotted on the same curves. The 0.17 second case failed due to floating point overflow. Thus, the Equation (1) rule of thumb is quite precise in providing the upper limit on time step size.

\section{CONCLUSIONS}

RELAP5-3D conduction enclosure model calculations were compared to exact solutions of the heat conduction equation. Three cases were chosen: (1) steady-state two-dimensional heat conduction in a rectangular solid; (2) transient one-dimensional conduction in a long, thin rod; and, (3) transient two-dimensional conduction in a 
Idaho Falls, ID

November 18-20, 2008

rectangular solid. It was shown that the heat conduction enclosure calculations with the RELAP5-3D code give excellent agreement with the exact solutions. It was also shown that Equation (1) can be used to determine the combination of time step size and conduction enclosure conductivity that gives a stable solution. Furthermore, a correction to the cylindrical and spherical heat conductor model in RELAP5-3D was identified as part of this analysis.

Limitations to the heat conduction enclosure model were also noted. It is noted that real problems may not be predicted as accurately as those analyzed in this paper, because the assumptions made to derive exact solutions to the heat conduction equation are consistent with the limitations in the heat conduction enclosure model. However, the conduction enclosure model can help identify when multi-dimensional heat conduction affects results.

\section{NOMENCLATURE}

$A=$ cross-sectional area $\left(\mathrm{m}^{2}\right)$

$\mathrm{a}=$ maximum $\mathrm{x}$-coordinate dimension $(\mathrm{m})$

$\mathrm{b}=$ maximum $\mathrm{y}$-coordinate dimension $(\mathrm{m})$

$\mathrm{c}=$ material specific heat $(\mathrm{J} / \mathrm{kg}-\mathrm{K})$

$\mathrm{H}=$ convective heat transfer coefficient $\left(\mathrm{W} / \mathrm{m}^{2}-\mathrm{K}\right)$

$\mathrm{k}=$ thermal conductivity $(\mathrm{W} / \mathrm{m}-\mathrm{K})$

$\ell=$ length $(\mathrm{m})$

$\mathrm{p}=$ perimeter $(\mathrm{m})$

$\mathrm{T}=$ temperature $(\mathrm{K})$

$\mathrm{T}_{0}=$ temperature at position or time zero $(\mathrm{K})$

$T_{\infty}=$ temperature of the surroundings or sides of the heat structure (K)

$\mathrm{t}=$ transient time (seconds)

$\mathrm{x}=\mathrm{x}$-coordinate in Cartesian coordinates (m)

$\mathrm{y}=\mathrm{y}$-coordinate in Cartesian coordinates (m)

$\alpha=$ thermal diffusivity ( $\left.\mathrm{m}^{2} / \mathrm{sec}\right)$

$\Delta \mathrm{t}=$ calculational time step size (sec)

$\Delta \mathrm{x}=$ conductor radial mesh size $(\mathrm{m})$

$v=\mathrm{Hp} / \rho \mathrm{\rho A}\left(\mathrm{sec}^{-1}\right)$

$\rho=$ material density $\left(\mathrm{kg} / \mathrm{m}^{3}\right)$

\section{REFERENCES}

Bayless, Paul, and Barber, Doug, “RELAP5-3D Developmental Assessment Plan”, Presented at RELAP5 International User’s Seminar, Idaho Falls, ID, November, 2007.

Carslaw, H. S., and Jaeger, J. C., Conduction of Heat in Solids, Second Edition, Oxford University Press, 1959.

Incropera, Frank P., and De Witt, David P., Fundamentals of Heat and Mass Transfer, Second Edition, John Wiley \& Sons, Inc., 1985.

Paik, Seungho, “RELAP5-3D Multidimensional Heat Conduction Enclosure Model for the RBMK Reactor Application”, Nuclear Technology, Volume 128, October, 1999. 